\title{
Monomer Connection Points
}

National Cancer Institute

\section{Source}

National Cancer Institute. Monomer Connection Points. NCI Thesaurus. Code C157466.

The atoms that make up the head and branch points within a single repeating

monomeric unit in a branched polymer. 